\title{
Mitigating the Impact of Admixtures in Thai Herbal Products
}

\author{
Santhosh Kumar J. Urumarudappa, Chayapol Tungphatthong and Suchada Sukrong ${ }^{\text {* }}$ \\ Research Unit of DNA Barcoding of Thai Medicinal Plants, Department of Pharmacognosy and Pharmaceutical Botany, \\ Faculty of Pharmaceutical Sciences, Chulalongkorn University, Bangkok, Thailand
}

Medicinal plants and their products are extensively used within indigenous healthcare systems in Thailand and several other nations. The international trade of herbal products has a noteworthy impact on the worldwide economy, and the interest in herbal products is expanding in both developing and developed countries. There has been rapid growth in the medicinal plant product market and a broadening consumer base interested in herbal products from Thailand. However, in herbal industries, ingredient substitution and admixture are typical issues wherein species of lower market value are admixed with those of a higher value. The adverse consequences of consuming adulterated drugs are invariably due to the presence of an unintended herb rather than the presence of an intended herb. It has also been argued that admixtures are intentional because of the lack of regulatory policies or centralized tests for product authentication. The consequences of species admixtures can extend from the reduced efficacy of a drug to decreased trade value. This study aims to clarify the nature and extent of species admixtures reported in the Thai herbal trade market and discuss the potential reasons for such adulteration. In the broader context of species admixtures, we strongly propose the establishment of multiple herbal crude drug repositories that can be developed to facilitate the use of comparative identity tests by industry, traders, and researchers to maintain authentic natural health product (NHP) standards and to certify the authenticity of NHPs. The proposition of the establishment of centralized testing (CT) could be a promising initiative in Thailand for the development of science and technology, and the herbal medicines produced as a result of CT could be dispensed as prescription drugs based on disease consideration instead of as health foods or nutraceuticals.

\section{Keywords: admixtures, adulterations, medicinal plants, Thai herbal products, herbal database}

\section{INTRODUCTION}

Medicinal plants contribute significantly to both the indigenous and modern systems of medicine. Since ancient times, medicinal plants have been used in traditional home remedies and have formed a major component of the indigenous system of medicine practiced in many countries. It has been reported that $80 \%$ of the world's population depend on traditional herbal medicines, mainly plantbased herbal drugs, for their primary healthcare (Srirama et al., 2017). The international trade of medicinal plants and their herbal products contributes to the worldwide economy; thus, the demand for such herbal products is growing in both developing and developed countries. More than 28,187 species of plants are used for medicinal purposes (Medicinal Plant Names Services Portal, 2017). 
These plants are used as either herbal medicines by the indigenous and rural communities or in the manufacture of pharmaceutical drugs. Currently, there are more than 1,000 herbal companies producing medicinal plant products, and their annual income is in excess of $\$ 60$ billion (Newmaster et al., 2013). Due to commercialization and increased demand for traditional herbs, safety, quality, and assurance are major issues (Chen et al., 2017).

In recent years, an international resurgence of attention has occurred in the use of herbal products in human healthcare, which has led the herbal product market to thrive (Barry and Abratt, 2015). The increase in demand has far outpaced the availability of raw materials. Thailand's major exports of medicinal plants are used in pharmaceutical, perfumery, etc. Estimated exports of herbal products from Thailand indicate an increase from US\$1.4 million in 2007 to US\$11.5 million in 2011 , recording a compounded annual growth rate of $12.67 \%$. The major export markets of Thai herbal extracts are Myanmar $(38.72 \%)$, the United States (13.15\%), Cambodia (10.92\%), Japan (9.50\%), the United Kingdom (6.79\%), and Hong Kong (3.31\%), whereas the import markets include China, Brazil, the United States, Germany, Philippines, and India (https://report. nat.gov.tw). However, due to high demands, the substitution and adulteration of many medicinal plant species in medicinal plant products (Techen et al., 2004; Song et al., 2009; Suwanchaikasem et al., 2013; Urumarudappa et al., 2016; Srirama et al., 2017; Dechbumroong et al., 2018; Kumar et al., 2018), breweries such as teas (Stoeckle et al., 2011), and "nutraceuticals" (Bruni et al., 2010; Jaakola et al., 2010) have been documented.

Medicinal plants used in raw herbal trade are often marketed as powders; dry twigs including dry roots, rhizomes, leaves, etc.; and pills or tablets, and thus are usually difficult to identify morphologically. The major problems with the trade of raw herbal products include the adulterations and substitution of certain species with morphologically similar and geographically co-occurring species (Ved and Goraya, 2007; Urumarudappa et al., 2016; Srirama et al., 2017). In most of the Southeast Asian countries, including Thailand, over $80 \%$ of the medicinal plants that are in active trade are seldom cultivated. These are collected largely from the wild. The collection of these medicinal plants is largely performed by local people who often rely only on their knowledge or experience in identifying the species being collected (Menon, 2003; Seethapathy et al., 2015; Srirama et al., 2017). Thus, most often, there are admixtures of related species or morphologically similar species in the herbal trade samples. The possible reasons for adulteration are often attributed to the apparent confusion associated with local or vernacular names of plant species, lack of accurate raw plant material, and identical morphological characters of co-occurring species of plants (Mitra and Kannan, 2007; Kumar et al., 2018). Admixture is a common malpractice in raw material trade and a major problem in the herbal industry. Admixture is the practice of substituting an authentic crude drug partially or entirely with a different drug similar to the original drug but inferior in therapeutic and synthetic properties or the addition of low-efficiency drugs for the intentional or unintentional enrichment of profits (Mukherjee, 2002; Kokate et al., 2007). The adverse consequences of consuming adulterated drugs are invariably due to the presence of an unintended herb rather than the presence of an intended herb (Sunita, 1992; Uniyal and Joshi, 1993; Sarin, 1996). It has also been argued that admixture is deliberate because there is no standard monitoring tool in place or commercial test for product authentication. The consequences of species admixtures can extend from the reduced efficiency of a drug to the decreased trade value (Wieniawski, 2001), in addition to a threat to the safety of consumers (Song et al., 2009).

Since adulteration is very difficult to trace in situ and requires expertise, scientific methods have been developed to address medicinal plant adulteration in herbal trade, such as microscopic, macroscopic, organoleptic, and chemical analyses (Techen et al., 2014; Moraes et al., 2015; Mishra et al., 2016; Pawar et al., 2017; Raclariu et al., 2018). DNA technology has been heavily used to investigate the adulteration of species (Newmaster et al., 2013; Phoolcharoen and Sukrong, 2013; Kumar et al., 2015; Urumarudappa et al., 2016; Pawar et al., 2017; Dechbumroong et al., 2018; Liu et al., 2018; Raclariu et al., 2018; Seethapathy et al., 2018; Speranskaya et al., 2018; Kreuzer et al., 2019). Among the available tools for species identification and traceability, DNA barcoding is a low-cost and highly efficient approach that has the potential for automatization and rapid application (Galimberti et al., 2013; Mishra et al., 2016; Dechbumroong et al., 2018).

In this review, we attempt to elucidate the nature and extent of species adulteration reported in the Thai herbal trade market and discuss the possible underlying causes of adulteration. In the larger context of species admixtures, we believe and propose the need to certify the centralized system to develop an efficient mechanism to systematically evaluate traditional medicine and connect it with both national and international trade regulators. We strongly suggest the establishment of several crude herbal drug depositories to maintain authentic biological reference materials (BRMs) that can be developed to facilitate the use of comparative identity tests by industry, traders, and researchers and to certify herbal product authenticity. We strongly recommend the enforcement of existing laws and regulations concerning the quality of herbal products to govern herbal trade around the globe. The proposed establishment of centralized testing (CT) could be a promising initiative in Thailand for the development of science and technology. The herbal medicines produced as a result of CT could be dispensed as prescription drugs based on disease consideration instead of being designated health foods or nutraceuticals. CT could pave the way to increase the country's market size of phytomedicine and become a novel strategy in Thailand as an important contributor to the herbal product market and to maintain the safety and health of consumers.

\section{MATERIALS AND METHODS}

\section{Literature Search on Medicinal Plants Used in Thai Herbal Pharmacopoeia (THP)}

In this study, the list of plants in Thailand Herbal Pharmacopoeia (THP) was the main focus. A literature search was performed with various electronic databases [Google Scholar, Science Direct 
(Scopus), and Web of Science] using specific search terms such as "Thai Herbal Pharmacopoeia mentioned plant names," "Thai medicinal plants," "Admixtures of Thai medicinal plants," and "Thai herbal medicine," which included peer-reviewed scientific studies and reports used to document traditional medicinal plants used in THP.

\section{Origin of Thai Traditional Medicine (TTM)}

Traditional medicines have been established after extensive experiences of over 100 years of practicing physicians in the indigenous systems of medicine (Kamboj, 2000). Traditional medicine of Thailand has an extensive history of use in various treatments and illnesses since the Sukhothai period (12381337) of Thai history. By the knowledge passed down through generations, a well-defined structure of traditional medicine has been developed, systematized, and is now recognized as Thai Traditional Medicine (TTM) by the Thailand Kingdom (SEARO, WHO, 2010). TTM is considered holistic medicine, as it involves not only the use and production of herbal medicine but also diagnosis, treatment, and pharmacy practice (Akarasereenont et al., 2015). The famous Thai massage (Nuad Thai) also originates from this system.

TTM draws its traditional content from the Indian and Chinese systems (WHO, 2002), as indicated by the diversity of ethnic groups in Thailand's population (Trisonthi and Trisonthi, 1995), possibly due to historic migration from neighboring countries (Phumthum and Balslev, 2018). Maintenance of unique and distinctive knowledge of medicinal plants has been seen mainly in these communities. Additionally, a study on a typical mountain-residing indigenous community named "Karen" showed that having limited access to public healthcare systems encouraged them to accumulate a valuable method of preventing and treating diseases with herbal remedies (Tangjitman et al., 2015). However, TTM observed a decline in consumer acceptance from 1916 to 1977 due to the influence of Western medicine, although a subsequent revival in acceptance was observed after the WHO advised that traditional medicine and plant herbal medicine should be implemented in primary healthcare systems (Akarasereenont et al., 2015). Then, to accelerate the integration of traditional medicine into national healthcare system, a list of the national essential herbal drugs (NEHD) was established in 1999 according to the National Drug Committee (2006). Today, the Thai government also funds and strongly supports medicinal plant research and development.

To reduce the cost of imported drugs and improve access to healthcare, ASEAN members agreed to implement the WHO's traditional medicine strategy (WHO, 2002) in the year 2004, which in turn enhanced the use of traditional medicine, especially herbal medicine, in ASEAN healthcare systems. A recent investigation reports that Thai people spend several million bahts per year on unproven herbal products (Osathanunkul et al., 2016). Currently, alternative medicines are popular not only in developing countries, such as Thailand and India, but also in developed countries, such as the United States, Canada, and Europe. In support of this, an estimate shows that the United States alone spends over US $\$ 5$ billion per year on herbal products (Osathanunkul et al., 2016). However, herbal products are considered supplements rather than medicines in the United States, which may be due to the absence of clinical data on their safety and efficacy.

\section{Species Admixtures in Herbal Trade: Thai Herbal Pharmacopoeia}

THP has listed 66 medicinal plants with a high therapeutic index as herbal medicine (Table 1). This study considered the listed medicinal plants to understand their status under the threat of adulteration in herbal trade (Table 2). A previous report has shown that $15.5 \%$ of the total number of plant species in Thailand is used as medicinal plants (Wakdikar, 2004). Recently, a number of studies have also shown that natural health product (NHP) market samples of raw herbal trade materials are often adulterated with other species (Kool et al., 2012; Newmaster et al., 2013; de Boer et al., 2015; Kumar et al., 2015; Urumarudappa et al., 2016; Mezzasalma et al., 2017; Pawar et al., 2017; Dechbumroong et al., 2018; Raclariu et al., 2018; Liu et al., 2018; Seethapathy et al., 2018; Speranskaya et al., 2018; Tungphatthong et al., 2018; Kreuzer et al., 2019).

A number of studies have reported species admixtures in herbal trade across countries. For example, DNA-based approaches have been used for the identification of species listed in Amazonian traditional medicine (Mezzasalma et al., 2017). Trachelospermum jasminoides is commonly used as traditional Chinese medicine and sold in markets in dried and sliced forms, which pose difficulties in traditional identification methods. Yu et al. (2017) used the nuclear region ITS2 to evaluate the 127 sequences representing $T$. jasminoides via the neighbor-joining tree method, which demonstrated the remarkable use of DNA barcoding to authenticate market samples. Using the ITS2 region, Chen et al. (2017) found that only 78\% of the market samples contained the species listed on their product label. A few studies showed the use of both molecular and chemical markers and phylogenetic approaches for the identification herbal products, including dietary supplements. For example, a study using a phylogenomic approach analyzed the evolutionarily complex genus Berberis in order to develop DNA barcodes for the medicinally important species Berberis aristata for the regulatory purposes and quality control (Kreuzer et al., 2019). The combination of molecular and chemical markers ensures the quality of the Copalchi complex used in Mexican Herbal Pharmacopoeia and successfully differentiates between the species Hintonia latiflora, $H$. standleyana, and Exostema caribaeum (Cristians et al., 2018). Pawar et al. (2017) used traditional DNA barcoding techniques and chemical markers to identify frequently consumed botanical dietary supplements of ginkgo, soy, valerian, yohimbe, etc. The combination of DNA barcoding and nuclear magnetic resonance (NMR) was used for the identification of admixture in Garciania species (Seethapathy et al., 2018) and Saraca acosa (Urumarudappa et al., 2016). Wang et al. (2016) used DNA barcoding for the identification of processed Angelicae sinensis radix (Danggui) used in Chinese patent medicines (CPMs). Lonicerae japonicae Flos was used to produce hundred kinds of CPMs, single nucleotide polymorphisms (SNPs) were used to generate 
TABLE 1 | Information on the 66 documented medicinal plants used in the Thailand Herbal Pharmacopoeia 2018.

\begin{tabular}{|c|c|c|c|c|c|}
\hline Thai name & Scientific name & Family & Habit & Parts used & Treatment/application \\
\hline $\begin{array}{l}\text { Wannam } \\
\text { (ว่านน้ำ) }\end{array}$ & Acorus calamus L. & Acoraceae & Aquatic perennial herb & Dried rhizome & Carminative \\
\hline $\begin{array}{l}\text { Matum } \\
\text { (มะตูม) }\end{array}$ & Aegle marmelos (L.) Corrêa & Rutaceae & Tree & Fruits and bark & Antidiarrheal, stomachic \\
\hline $\begin{array}{l}\text { Hom } \\
\text { (หอม) }\end{array}$ & Allium ascalonicum L. & Amaryllidaceae & Biennial herb & Dried bulb & Carminative, expectorant \\
\hline $\begin{array}{l}\text { Krathiam } \\
\text { (กระเทียม) }\end{array}$ & Allium sativum $\mathrm{L}$. & Amaryllidaceae & Herb & Bulb & Antimicrobial, antihyperlipidemic \\
\hline $\begin{array}{l}\text { Fa Thalai } \\
\text { (ฟ้าทะลายโจร) }\end{array}$ & $\begin{array}{l}\text { Andrographis paniculata } \\
\text { (Burm. f.) Nees }\end{array}$ & Acanthaceae & Herb & Dried aerial part & $\begin{array}{l}\text { Antidiarrheal, antipyretic, } \\
\text { antiinflammatory }\end{array}$ \\
\hline $\begin{array}{l}\text { Thian Ta Takkatan } \\
\text { (เทียนตาต๊กแตน) }\end{array}$ & Anethum graveolens L. & Apiaceae & Annual herb & Dried ripe fruit & Carminative, pharmaceutic aid \\
\hline (โกฐูสอ) & $\begin{array}{l}\text { Angelica dahurica (Hoffm.) } \\
\text { Benth. \& H }\end{array}$ & Apiaceae & Perennial herb & Dried root & Antipyretic, analgesic \\
\hline $\begin{array}{l}\text { Kot Chiang } \\
\text { (โกฐเชียง) }\end{array}$ & Angelica sinensis (Oliv.) Diels & Apiaceae & Perennial herb & Roots & $\begin{array}{l}\text { Blood tonic, treatment of mental } \\
\text { disorders }\end{array}$ \\
\hline $\begin{array}{l}\text { Khamin Khruea } \\
\text { (ขมิ้นเครือ) }\end{array}$ & Arcangelisia flava (L.) Merr. & Menispermaceae & Large climber & Stem & $\begin{array}{l}\text { Stomachic, antidiarrheal, } \\
\text { antibacterial }\end{array}$ \\
\hline $\begin{array}{l}\text { Maksong } \\
\text { (หมากสง) }\end{array}$ & Areca catechu L. & Areceae & $\begin{array}{l}\text { Small or medium sized } \\
\text { tree }\end{array}$ & Ripe seed & Anthelmintic, antidiarrheal, \\
\hline $\begin{array}{l}\text { Kot Chula Lampha } \\
\text { (โกฐจุฬำลัมพา) }\end{array}$ & Artemisia annua L. & Asteraceae & Annual herb & Dried aerial part & Antipyretic \\
\hline $\begin{array}{l}\text { Kot Khamao } \\
\text { (โกฐเขมา) }\end{array}$ & $\begin{array}{l}\text { Atractylodes lancea (Thunb.) } \\
\text { DC. }\end{array}$ & Asteraceae & Perennial herb & Rhizome & Stomachic \\
\hline $\begin{array}{l}\text { Kot Kraduk } \\
\text { (โกฐกระดูก) }\end{array}$ & Aucklandia lappa Decne & Asteraceae & Herb & Roots & $\begin{array}{l}\text { Stomachic, carminative, } \\
\text { antispasmodic }\end{array}$ \\
\hline Sawat & $\begin{array}{l}\text { Caesalpinia bonduc (L.) H. } \\
\text { Roxb. }\end{array}$ & Fabaceae & Climber & Leaf & Laxative, antiflatulent \\
\hline $\begin{array}{l}\text { Phrik Khinu } \\
\text { (พริกขึหนู) }\end{array}$ & Capsicum annuum L. & Solanaceae & $\begin{array}{l}\text { Annual or perennial } \\
\text { herb }\end{array}$ & Dried ripe fruit & $\begin{array}{l}\text { Gastro-intestinal stimulant, } \\
\text { counterirritant }\end{array}$ \\
\hline $\begin{array}{l}\text { Thian Ta Kop } \\
\text { (เทียนตากบ) }\end{array}$ & Carum carvi L. & Apiaceae & Perennial herb & Dried ripe fruit & $\begin{array}{l}\text { Carminative, antiflatulent, } \\
\text { pharmaceutic aid }\end{array}$ \\
\hline $\begin{array}{l}\text { Khun } \\
\text { (คูน) }\end{array}$ & Cassia fistula L. & Fabaceae & Tree & Pulp & Laxative \\
\hline (บัวบก) & Centella asiatica (L.) Urb. & Apiaceae & Herb & Aerial part & $\begin{array}{l}\text { Mild diuretic, antiinflammatory, } \\
\text { wound healing }\end{array}$ \\
\hline $\begin{array}{l}\text { Phet Sangkhat } \\
\text { (เพชรสังฆาต) }\end{array}$ & Cissus quadrangularis L. & Vitaceae & Woody climber & Dried stem & $\begin{array}{l}\text { Alleviation of hemorrhoidal } \\
\text { symptoms }\end{array}$ \\
\hline $\begin{array}{l}\text { Makrut } \\
\text { (มะกรูด) }\end{array}$ & Citrus hystrix DC. & Rutaceae & Shrub or small tree & Leaf & Pharmaceutics aid, carminative \\
\hline $\begin{array}{l}\text { Phaya Yo } \\
\text { (พญายอ) }\end{array}$ & $\begin{array}{l}\text { Clinacanthus nutans (Burm. } \\
\text { f.) Lindau }\end{array}$ & Acanthaceae & Scandent shrub & Leaf & Antiinflammatory, antiviral \\
\hline $\begin{array}{l}\text { Thian Khao } \\
\text { (เทียนขาว) }\end{array}$ & Cuminum cyminum L. & Apiaceae & Herb & Fruit & $\begin{array}{l}\text { Carminative, expectorant, } \\
\text { alterative }\end{array}$ \\
\hline $\begin{array}{l}\text { Khamin Chan } \\
\text { (ขมีนชัน) }\end{array}$ & Curcuma longa L. & Zingiberaceae & Perennial herb & Dried rhizome & $\begin{array}{l}\text { Stomachic, carminative, } \\
\text { pharmaceutics aid, astringent }\end{array}$ \\
\hline Khamin Oi & Curcuma sp. & Zingiberaceae & Perennial herb & Dried rhizome & $\begin{array}{l}\text { Stomachic, antidiarrheal, } \\
\text { emmenagogue }\end{array}$ \\
\hline $\begin{array}{l}\text { Lakkachan } \\
\text { (ลักจัน) }\end{array}$ & $\begin{array}{l}\text { Dracaena cochinchinensis } \\
\text { (Lour.) S. C. Chen }\end{array}$ & Asparagaceae & Tree & Wood & Antipyretic, antiinflammatory \\
\hline $\begin{array}{l}\text { Pla Lai Phueak } \\
\text { (ปลาไหลเผือก) }\end{array}$ & Eurycoma longifolia Jack & Simaroubaceae & Shrub & Roots & Antipyretic \\
\hline $\begin{array}{l}\text { Thian Khao Plueak } \\
\text { (เทียนข้าวเปลือก) }\end{array}$ & Foeniculum vulgare Mill. & Apiaceae & Herb & $\begin{array}{l}\text { Dried cremocarp } \\
\text { and mericarp }\end{array}$ & Carminative, spasmolytic \\
\hline $\begin{array}{l}\text { Krachiap Daeng } \\
\text { (กระเจียบแดง) }\end{array}$ & Hibiscus sabdariffa L. & Malvaceae & $\begin{array}{l}\text { Annual herb or } \\
\text { subshrub }\end{array}$ & $\begin{array}{l}\text { Dried persistent } \\
\text { calyx and epicalyx }\end{array}$ & Diuretic \\
\hline $\begin{array}{l}\text { Maenglak Kha } \\
\text { (แมงลักคา) }\end{array}$ & Hyptis suaveolens (L.) Poit. & Lamiaceae & Shrub & Dried aerial part & $\begin{array}{l}\text { Carminative, antimicrobial } \\
\text { (topical) }\end{array}$ \\
\hline $\begin{array}{l}\text { Krachai Dam } \\
\text { (กระชายดำ) }\end{array}$ & $\begin{array}{l}\text { Kaempferia parviflora Wall. } \\
\text { ex Baker. }\end{array}$ & Zingiberaceae & Herb & Rhizome & Tonic, carminative \\
\hline $\begin{array}{l}\text { Thian Daeng } \\
\text { (เทียนแดง) }\end{array}$ & Lepidium sativum L. & Brassicaceae & Annual herb & Seeds & Expectorant, stomachic \\
\hline $\begin{array}{l}\text { Kot Hua Bua } \\
\text { (โกฐหัวบัว) }\end{array}$ & $\begin{array}{l}\text { Ligusticum sinense Oliv. cv. } \\
\text { Chuanxiong }\end{array}$ & Apiaceae & Herb & Dried Rhizome & $\begin{array}{l}\text { Carminative, blood tonic for } \\
\text { menstrual disorder }\end{array}$ \\
\hline Bunnak & Mesua ferrea $L$. & Calophyllaceae & Tree & $\begin{array}{l}\text { Dried blooming } \\
\text { flower }\end{array}$ & Cardiotonic, antipyretic \\
\hline
\end{tabular}


TABLE 1 | Continued

\begin{tabular}{|c|c|c|c|c|c|}
\hline Thai name & Scientific name & Family & Habit & Parts used & Treatment/application \\
\hline $\begin{array}{l}\text { Phikun } \\
\text { (พิกุล) }\end{array}$ & Mimusops elengi L. & Sapotaceae & Tree & Dried flower & Tonic, antipyretic \\
\hline $\begin{array}{l}\text { Mara Khi Nok } \\
\text { (มะระขี้นก) }\end{array}$ & Momordica charantia L. & Cucurbitaceae & $\begin{array}{l}\text { Annual or perennial } \\
\text { climber }\end{array}$ & Fruit & $\begin{array}{l}\text { Bitter tonic, internal heat } \\
\text { alleviating }\end{array}$ \\
\hline $\begin{array}{l}\text { Mon } \\
\text { (หม่อน) }\end{array}$ & Morus alba L. & Moraceae & $\begin{array}{l}\text { Deciduous tree or } \\
\text { shrub }\end{array}$ & Leaf & Mild antitussive \\
\hline $\begin{array}{l}\text { Kot Chada Mangsi } \\
\text { (โกฐซฎามังสี) }\end{array}$ & $\begin{array}{l}\text { Nardostachys jatamansi (D. } \\
\text { Don) DC. }\end{array}$ & Caprifoliaceae & herb & Roots, Rhizome & $\begin{array}{l}\text { Mild sedative, treatment of } \\
\text { dysmenorrhea }\end{array}$ \\
\hline $\begin{array}{l}\text { Bua Luang } \\
\text { (บัวหลวง) }\end{array}$ & Nelumbo nucifera Gaertn. & Nelumbonaceae & Perennial herb & Dried stamen & Cardiotonic, antipyretic \\
\hline $\begin{array}{l}\text { Kot Kan Phrao } \\
\text { (โกฐก้านพร้าว) }\end{array}$ & $\begin{array}{l}\text { Neopicrorhiza scrophularia } \\
\text { Pennell }\end{array}$ & Plantaginaceae & Perennial herb & Rhizome & Antipyretic, stomachic \\
\hline $\begin{array}{l}\text { Thian Dam } \\
\text { (เทียนดำ) }\end{array}$ & Nigella sativa L. & Ranunculaceae & Annual herb & Seed & Carminative, diuretic \\
\hline $\begin{array}{l}\text { Kaphrao Daeng } \\
\text { (กะเพราแดง) }\end{array}$ & Ocimum tenuiflorum L. & Lamiaceae & Herb & Dried leaf & Pharmaceutics aid, carminative \\
\hline $\begin{array}{l}\text { Ya Nuat Maeo } \\
\text { (หญ้าหนวดแมว) }\end{array}$ & $\begin{array}{l}\text { Orthosiphon aristatus } \\
\text { (Blume) Miq. }\end{array}$ & Lamiaceae & Perennial herb & $\begin{array}{l}\text { Dried leaf and } \\
\text { stem tip }\end{array}$ & Diuretic \\
\hline $\begin{array}{l}\text { Makham Pom } \\
\text { (มะขามป้อม) }\end{array}$ & Phyllanthus emblica L. & Phyllanthaceae & $\begin{array}{l}\text { Small or medium sized } \\
\text { tree }\end{array}$ & Dried mature fruit & $\begin{array}{l}\text { Expectorant, laxative, } \\
\text { antiscorbutic }\end{array}$ \\
\hline $\begin{array}{l}\text { Thian Sattabut } \\
\text { (เทียนสัตตบุษย์) }\end{array}$ & Pimpinella anisum L. & Apiaceae & Annual herb & Dried ripe fruit & $\begin{array}{l}\text { Carminative, expectorant, } \\
\text { pharmaceutic aid }\end{array}$ \\
\hline $\begin{array}{l}\text { Phlu } \\
\text { (พลู) }\end{array}$ & Piper betle L. & Piperaceae & Woody climber & Leaf & Antifungal, antiallergic \\
\hline $\begin{array}{l}\text { Phrik Thai Dam } \\
\text { (พริกไทยดำ) }\end{array}$ & Piper nigrum L. & Piperaceae & Climber & fruit & Aromatic, stomachic, carminative \\
\hline $\begin{array}{l}\text { Phrik Thai Lon } \\
\text { (พริกไทยล่อน) }\end{array}$ & Piper nigrum L. & Piperaceae & $\begin{array}{l}\text { Woody perennial } \\
\text { climber }\end{array}$ & Dried unripe fruit & Aromatic, stomachic, carminative \\
\hline $\begin{array}{l}\text { Di Pli } \\
\text { (ดีปลี) }\end{array}$ & Piper retrofractum Vahl & Piperaceae & Woody climber & Dried stem & $\begin{array}{l}\text { Carminative, stomachic, } \\
\text { antiinflammatory }\end{array}$ \\
\hline $\begin{array}{l}\text { Chaphlu } \\
\text { (ชะพลู) }\end{array}$ & Piper sarmentosum Roxb. & Piperaceae & Herb & Leaf & Carminative \\
\hline $\begin{array}{l}\text { Sakhan } \\
\text { (สะค้าน) }\end{array}$ & $\begin{array}{l}\text { Piper wallichii (Miq.) } \\
\text { Hand.-Mazz. }\end{array}$ & Piperaceae & Woody climber & Dried stem & $\begin{array}{l}\text { Carminative, stomachic, } \\
\text { antiinflammatory }\end{array}$ \\
\hline $\begin{array}{l}\text { Thian Klet Hoi } \\
\text { (เทียนเกล็ดหอย) }\end{array}$ & Plantago ovata Forssk. & Plantaginaceae & Herb & Seed & Bulk-forming laxative \\
\hline $\begin{array}{l}\text { Chan Daeng } \\
\text { (จันทน์แดง) }\end{array}$ & Pterocarpus santalinus L. f. & Fabaceae & Tree & Bark & $\begin{array}{l}\text { Antipyretic, antiinflammatory, } \\
\text { cardiotonic }\end{array}$ \\
\hline $\begin{array}{l}\text { Chan Khao } \\
\text { (จันทน์ขาว) }\end{array}$ & Santalum album L. & Santalaceae & Tree & Dried heartwood & $\begin{array}{l}\text { Cardiotonic, stomachic, nerve } \\
\text { tonic }\end{array}$ \\
\hline $\begin{array}{l}\text { Chumhet Thet } \\
\text { (ชุมเห็ดเทศ) }\end{array}$ & Senna alata (L.) Roxb. & Fabaceae & Herb or under shrub & Dried mature seed & Laxative, antifungal \\
\hline $\begin{array}{l}\text { Chumhet Thai } \\
\text { (ซุมเห็ดไทย) }\end{array}$ & Senna tora (L.) Roxb. & Fabaceae & Herb or under shrub & Dried mature seed & Laxative, diuretic \\
\hline $\begin{array}{l}\text { Mawaeng Khruea } \\
\text { (มะแว้งเคืือ) }\end{array}$ & Solanum trilobatum L. & Solanaceae & $\begin{array}{l}\text { Slender scrambling } \\
\text { shrub }\end{array}$ & Fruit & Expectorant \\
\hline $\begin{array}{l}\text { Thaowan Priang } \\
\text { (เถาวัลย์เปรียง) }\end{array}$ & $\begin{array}{l}\text { Solori scandens (Roxb.) } \\
\text { Sirich. \& Ade }\end{array}$ & Fabaceae & Large woody Climber & Dried stem & Analgesic, antiinflammatory, \\
\hline $\begin{array}{l}\text { Tanmon } \\
\text { (ตานหม่อน) }\end{array}$ & $\begin{array}{l}\text { Tarlmounia elliptica (DC.) H. } \\
\text { Rob., S. C. }\end{array}$ & Asteraceae & Scandent shrub & Leaf & Demulcent \\
\hline $\begin{array}{l}\text { Samo Phiphek } \\
\text { (สมอพิเภก) }\end{array}$ & $\begin{array}{l}\text { Terminalia bellirica (Gaertn.) } \\
\text { Roxb. }\end{array}$ & Combretaceae & Large tree & Mature fruit & $\begin{array}{l}\text { Laxative, carminative, astringent, } \\
\text { expectorant }\end{array}$ \\
\hline $\begin{array}{l}\text { Samo Thai, Kot Phung Pla } \\
\text { (สมอไทย, โกฐพุงปลา) }\end{array}$ & Terminalia chebula Retz. & Combretaceae & Large tree & Mature fruit & $\begin{array}{l}\text { Laxative, carminative, astringent, } \\
\text { expectorant }\end{array}$ \\
\hline $\begin{array}{l}\text { Rangchuet } \\
\text { (รางจืด) }\end{array}$ & Thunbergia laurifolia Lindl. & Acanthaceae & Woody climber & Leaf & Detoxicant, antipyretic \\
\hline $\begin{array}{l}\text { Boraphet } \\
\text { (บอระเพ็ด) }\end{array}$ & $\begin{array}{l}\text { Tinospora crispa (L.) Hook. } \\
\text { f. \& Thom }\end{array}$ & Menispermaceae & Woody climber & Dried stem & $\begin{array}{l}\text { Antipyretic, bitter tonic, } \\
\text { stomachic }\end{array}$ \\
\hline $\begin{array}{l}\text { Thian Yaowaphani } \\
\text { (เทียนเยาวพาณี) }\end{array}$ & $\begin{array}{l}\text { Trachyspermum ammi (L.) } \\
\text { Sprague }\end{array}$ & Apiaceae & Annual herb & Dried ripe fruit & Carminative, pharmaceutic aid \\
\hline $\begin{array}{l}\text { Phlai } \\
\text { (ไพล) }\end{array}$ & $\begin{array}{l}\text { Zingiber montanum (J. } \\
\text { König) Link. ex A. }\end{array}$ & Zingiberaceae & Herb & Dried rhizome & $\begin{array}{l}\text { Antiinflammatory, counterirritant, } \\
\text { mosquito repellent }\end{array}$ \\
\hline $\begin{array}{l}\text { Khing } \\
\text { (ขิง) }\end{array}$ & Zingiber officinale Roscoe & Zingiberaceae & Perennial herb & Dried rhizome & Carminative, antiflatulent \\
\hline $\begin{array}{l}\text { Krathue } \\
\text { (กระทื่อ) }\end{array}$ & Zingiber zerumbet (L.) Sm. & Zingiberaceae & Herb & Dried rhizome & Antiflatulent, stomachic \\
\hline
\end{tabular}


TABLE 2 | Species admixtures in the herbal trade samples of medicinal plants listed in the Thai Herbal Pharmacopoeia and techniques employed for discrimination.

\begin{tabular}{|c|c|c|c|c|c|c|c|}
\hline Thai name & Scientific name & Matrix type & $\begin{array}{l}\text { Total } \\
\text { number } \\
\text { samples }\end{array}$ & $\begin{array}{l}\text { Percentage } \\
\text { of species } \\
\text { admixture } \\
\text { detected }\end{array}$ & $\begin{array}{l}\text { Declared/ } \\
\text { identified species }\end{array}$ & $\begin{array}{l}\text { Discriminant } \\
\text { technique } \\
\text { employed }\end{array}$ & Reference \\
\hline $\begin{array}{l}\text { Maksong } \\
\text { (หมากสง) }\end{array}$ & Areca catechu L. & $\begin{array}{l}\text { Processed } \\
\text { sample }\end{array}$ & 45 & 38.09 & Nil & Mini-DNA barcode & Song et al., 2017 \\
\hline $\begin{array}{l}\text { Matum } \\
\text { (มะตูม) }\end{array}$ & $\begin{array}{l}\text { Aegle maamelos, } \\
\text { (L.) Corrêa }\end{array}$ & Leaf, root, fruit & 11 & 0 & Nil & DNA barcode & Kumar et al., 2018 \\
\hline $\begin{array}{l}\text { Fa Thalai } \\
\text { (ฟ้าทะลาย) }\end{array}$ & $\begin{array}{l}\text { Andrographis } \\
\text { paniculata } \\
\text { (Burm.f.) Nees }\end{array}$ & $\begin{array}{l}\text { Dried sample, } \\
\text { powder, } \\
\text { capsule, tea }\end{array}$ & 10 & $N Q$ & $\begin{array}{l}\text { Andrographis } \\
\text { paniculata, Acanthus } \\
\text { ebracteatus and } \\
\text { Rhinacanthus } \\
\text { nasutus }\end{array}$ & DNA barcode & $\begin{array}{l}\text { Osathanunkul } \\
\text { et al., } 2016\end{array}$ \\
\hline $\begin{array}{l}\text { Thian Ta Takkatan } \\
\text { (เทียนตาตั้กแตน) }\end{array}$ & $\begin{array}{l}\text { Anethum } \\
\text { graveolens L. }\end{array}$ & $\mathrm{N} / \mathrm{A}$ & $\mathrm{N} / \mathrm{A}$ & $N Q$ & $\begin{array}{l}\text { Trachyspermum } \\
\text { ammi andFoeniculum } \\
\text { vulgare }\end{array}$ & DNA barcode & $\begin{array}{l}\text { Schori and } \\
\text { Showalter, } 2001\end{array}$ \\
\hline $\begin{array}{l}\text { Kot } \\
\text { (โกฐสอ) }\end{array}$ & $\begin{array}{l}\text { Angelica dahurica } \\
\text { (Hoffm.) Benth. } \\
\text { \& Hook.f. ex } \\
\text { Franch. \& Sav. }\end{array}$ & Root & $\mathrm{N} / \mathrm{A}$ & $N Q$ & Nil & $\begin{array}{l}\text { Metabarcoding } \\
\text { and real-time PCR }\end{array}$ & Xin et al., 2018 \\
\hline $\begin{array}{l}\text { Kot } \\
\text { (โกฐสอ) }\end{array}$ & $\begin{array}{l}\text { Angelica dahurica } \\
\text { (Hoffm.) Benth. } \\
\text { \& Hook.f. ex } \\
\text { Franch. \& Sav. }\end{array}$ & Root & 20 & $N Q$ & $\begin{array}{l}\text { A. anomala and } A \text {. } \\
\text { japonica }\end{array}$ & $\begin{array}{l}\text { DNA barcode and } \\
\text { SCAR assay }\end{array}$ & Noh et al., 2018 \\
\hline $\begin{array}{l}\text { Kot Chiang } \\
\text { (โกฐเชียง) }\end{array}$ & $\begin{array}{l}\text { Angelica sinensis } \\
\text { (Oliv.) Diels }\end{array}$ & $\mathrm{N} / \mathrm{A}$ & $\mathrm{N} / \mathrm{A}$ & $N Q$ & $\begin{array}{l}\text { A. laxifoliata and } A \text {. } \\
\text { nitida }\end{array}$ & DNA barcode & Feng et al., 2010 \\
\hline $\begin{array}{l}\text { Kot Chiang } \\
\text { (โกฐเซียง) }\end{array}$ & $\begin{array}{l}\text { Angelica sinensis } \\
\text { (Oliv.) Diels }\end{array}$ & Root & 13 & $N Q$ & Nil & HPLC fingerprints & Lu et al., 2005 \\
\hline $\begin{array}{l}\text { Kot Chula Lampha } \\
\text { (โกฐจุฬำลัมพา) }\end{array}$ & $\begin{array}{l}\text { Artemisia annua } \\
\text { Pall. }\end{array}$ & $\begin{array}{l}\text { Dried herb, } \\
\text { powder, tablet, } \\
\text { tea }\end{array}$ & 58 & $N Q$ & $\begin{array}{l}\text { A. atrovirens and } A \text {. } \\
\text { indica }\end{array}$ & $\begin{array}{l}\text { High resolution } \\
\text { melting (HRM) } \\
\text { curve analysis and } \\
\text { DNA barcode }\end{array}$ & Song et al., 2016 \\
\hline $\begin{array}{l}\text { Phrik Khinu } \\
\text { (พริกขึ้หนู) }\end{array}$ & $\begin{array}{l}\text { Capsicum } \\
\text { annuum L. }\end{array}$ & Powder & 5 & $N Q$ & $\begin{array}{l}\text { Beta vulgaris and } \\
\text { Ziziphus nummularia }\end{array}$ & $\begin{array}{l}\text { RAPD-PCR and } \\
\text { SCAR markers }\end{array}$ & $\begin{array}{l}\text { Dhanya et al., } \\
2011\end{array}$ \\
\hline $\begin{array}{l}\text { Phrik Khinu } \\
\text { (พริกขี้หนู) }\end{array}$ & $\begin{array}{l}\text { Capsicum } \\
\text { annuum L. }\end{array}$ & Powder & 61 & 14.75 & $\begin{array}{l}\text { Garlic, spring onion, } \\
\text { and/or onion }\end{array}$ & $\begin{array}{l}\text { Real-time PCR and } \\
\text { DNA sequencing }\end{array}$ & Kang, 2018 \\
\hline $\begin{array}{l}\text { Khun } \\
\text { (คูน) }\end{array}$ & Cassia fistula L. & $\begin{array}{l}\text { Dried herb, } \\
\text { powder, }\end{array}$ & 12 & 0 & Nil & DNA barcode & $\begin{array}{l}\text { Seethapathy et al., } \\
2015\end{array}$ \\
\hline $\begin{array}{l}\text { Thian Khao, Yira } \\
\text { (เทียนขาว/ยีหร่) }\end{array}$ & $\begin{array}{l}\text { Cuminum } \\
\text { cyminum L. }\end{array}$ & Powder & 11 & $N Q$ & Nil & DNA barcode & Arunraj et al., 2016 \\
\hline $\begin{array}{l}\text { Khamin Chan } \\
\text { (ขมิ้นชัน) }\end{array}$ & Curcuma longa L. & $\begin{array}{l}\text { Dried and fresh } \\
\text { plant tissue }\end{array}$ & 7 & 58.54 & Nil & $\begin{array}{l}\text { Bar-HRM } \\
\text { technique }\end{array}$ & $\begin{array}{l}\text { Osathanunkul } \\
\text { et al., } 2017\end{array}$ \\
\hline $\begin{array}{l}\text { Pla Lai Phueak } \\
\text { (ปลาไหลเผือก) }\end{array}$ & $\begin{array}{l}\text { Eurycoma } \\
\text { longifolia Jack }\end{array}$ & Root powder & 46 & 50 or more & Nil & $\begin{array}{l}\text { HPLC and } \\
\text { two-dimensional } \\
\text { electrophoresis } \\
\text { (2DE) }\end{array}$ & $\begin{array}{l}\text { Vejayan et al., } \\
2018\end{array}$ \\
\hline $\begin{array}{l}\text { Pla Lai Phueak } \\
\text { (ปลาไหลเผือก) }\end{array}$ & $\begin{array}{l}\text { Eurycoma } \\
\text { longifolia Jack }\end{array}$ & $\begin{array}{l}\text { Capsule, tablet, } \\
\text { tea }\end{array}$ & 11 & 27 & $\begin{array}{l}\text { Holcoglossum sp., } \\
\text { Nigella arvensis, } \\
\text { Nigella sativa, and } \\
\text { Ficus deltoidea }\end{array}$ & $\begin{array}{l}\text { DNA barcode and } \\
\text { HPLC analysis }\end{array}$ & $\begin{array}{l}\text { Abubakar et al., } \\
2018\end{array}$ \\
\hline $\begin{array}{l}\text { Pla Lai Phueak } \\
\text { (ปลาไหลเผือก) }\end{array}$ & $\begin{array}{l}\text { Eurycoma } \\
\text { longifolia Jack }\end{array}$ & $\begin{array}{l}\text { Capsule, } \\
\text { beverage, } \\
\text { instant coffee } \\
\text { mix, tea }\end{array}$ & 11 & $N Q$ & Nil & Bar-HRM analysis & Fadzil et al., 2018 \\
\hline $\begin{array}{l}\text { Krachai Dam, Thai } \\
\text { Ginseng } \\
\text { (กระชายดำ) }\end{array}$ & $\begin{array}{l}\text { Kaempferia } \\
\text { parviflora Wall. ex } \\
\text { Baker }\end{array}$ & $\begin{array}{l}\text { Processed } \\
\text { and packed } \\
\text { commercial } \\
\text { powder }\end{array}$ & 7 & 58.54 & Nil & Bar-HRM analysis & $\begin{array}{l}\text { Osathanunkul } \\
\text { et al., } 2017\end{array}$ \\
\hline $\begin{array}{l}\text { Bunnak } \\
\text { (บุนนาค) }\end{array}$ & Mesua ferrea L. & Crude drug & 6 & 33 & Nil & DNA barcode & Kumar et al., 2018 \\
\hline $\begin{array}{l}\text { Thian Dam } \\
\text { (เทียนดำ) }\end{array}$ & Nigella sativa L. & Seed & 10 & $N Q$ & $\begin{array}{l}\text { Allium cepa and } \\
\text { Clitoria guianensis }\end{array}$ & DNA barcode & Sudhir et al., 2016 \\
\hline
\end{tabular}


TABLE 2 | Continued

\begin{tabular}{|c|c|c|c|c|c|c|c|}
\hline Thai name & Scientific name & Matrix type & $\begin{array}{l}\text { Total } \\
\text { number } \\
\text { samples }\end{array}$ & $\begin{array}{l}\text { Percentage } \\
\text { of species } \\
\text { admixture } \\
\text { detected }\end{array}$ & $\begin{array}{l}\text { Declared/ } \\
\text { identified species }\end{array}$ & $\begin{array}{l}\text { Discriminant } \\
\text { technique } \\
\text { employed }\end{array}$ & Reference \\
\hline $\begin{array}{l}\text { Thian Dam } \\
\text { (เทียนดำ) }\end{array}$ & Nigella sativa L. & Seed oil & N/A & $N Q$ & Grape seed oil & $\begin{array}{l}\text { Fourier transform } \\
\text { infrared (FTIR) } \\
\text { spectroscopy } \\
\text { and gas } \\
\text { chromatography }\end{array}$ & $\begin{array}{l}\text { Nurrulhidayah } \\
\text { et al., } 2011\end{array}$ \\
\hline $\begin{array}{l}\text { Phrik Thai } \\
\text { (พริกไทย) }\end{array}$ & Piper nigrum L. & Fruit & N/A & $\mathrm{NQ}$ & Carica papaya & $\begin{array}{l}\text { HPLC and } \\
\text { antioxidative assay } \\
\text { markers }\end{array}$ & $\begin{array}{l}\text { Menghani et al., } \\
2010\end{array}$ \\
\hline $\begin{array}{l}\text { Phrik Thai } \\
\text { (พริกไทย) }\end{array}$ & Piper nigrum L. & Powder & 9 & $\mathrm{NQ}$ & Chili & $\begin{array}{l}\text { DNA barcode and } \\
\text { HPLC }\end{array}$ & $\begin{array}{l}\text { Parvathy et al., } \\
2014\end{array}$ \\
\hline $\begin{array}{l}\text { Phrik Thai } \\
\text { (พริกไทย) }\end{array}$ & Piper nigrum L. & Seed & $\mathrm{N} / \mathrm{A}$ & $\mathrm{NQ}$ & Carica papaya & RAPD markers & Khan et al., 2010 \\
\hline $\begin{array}{l}\text { Chan Khao } \\
\text { (จันทน์ขาว) }\end{array}$ & $\begin{array}{l}\text { Santalum album } \\
\mathrm{L} .\end{array}$ & Oil & 38 & $\mathrm{NQ}$ & Nil & $\begin{array}{l}\text { Gas } \\
\text { chromatography- } \\
\text { mass spectrometry }\end{array}$ & Howes et al., 2004 \\
\hline $\begin{array}{l}\text { Chan Khao } \\
\text { (จันทน์ขาว) }\end{array}$ & $\begin{array}{l}\text { Santalum album } \\
\mathrm{L} .\end{array}$ & Oil & 6 & $\mathrm{NQ}$ & Nil & $\begin{array}{l}\text { Multidimensional } \\
\text { gas } \\
\text { chromatography } \\
\text { with simultaneous } \\
\text { mass } \\
\text { spectrometric and } \\
\text { flame ionization } \\
\text { detection }\end{array}$ & $\begin{array}{l}\text { Sciarrone et al., } \\
2011\end{array}$ \\
\hline $\begin{array}{l}\text { Samo phiphek } \\
\text { (สมอพิเภก) }\end{array}$ & $\begin{array}{l}\text { Terminalia billirica } \\
\text { (Gaertn.) Roxb. }\end{array}$ & Fruit & 10 & 0 & Nil & DNA barcode & Kumar et al., 2018 \\
\hline $\begin{array}{l}\text { Samo phiphek } \\
\text { (สมอพิเภก) }\end{array}$ & $\begin{array}{l}\text { Terminalia bellirica } \\
\text { (Gaertn.) Roxb. }\end{array}$ & Crude drug & 12 & $N Q$ & Nil & $\begin{array}{l}\text { PCR-RFLP and } \\
\text { amplification } \\
\text { refractory mutation } \\
\text { system (ARMS) }\end{array}$ & $\begin{array}{l}\text { Intharuksa et al., } \\
2016\end{array}$ \\
\hline $\begin{array}{l}\text { Samo Thai } \\
\text { (สมอไทย) }\end{array}$ & $\begin{array}{l}\text { Terminalia } \\
\text { chubula Retz. }\end{array}$ & Fruit & 13 & 0 & Nil & DNA barcode & Kumar et al., 2018 \\
\hline $\begin{array}{l}\text { Samo Thai } \\
\text { (สมอไทย) }\end{array}$ & $\begin{array}{l}\text { Terminalia } \\
\text { chebula Retz. }\end{array}$ & Immature fruit & N/A & $N Q$ & Nil & $\begin{array}{l}\text { Chromatographic } \\
\text { fingerprint analysis }\end{array}$ & Xie et al., 2006 \\
\hline $\begin{array}{l}\text { Rangchuet } \\
\text { (รางจืด) }\end{array}$ & $\begin{array}{l}\text { Thunbergia } \\
\text { laurifolia Lindl. }\end{array}$ & Leaf & 8 & $N Q$ & Nil & PCR-RFLP & $\begin{array}{l}\text { Suwanchaikasem } \\
\text { et al., } 2013\end{array}$ \\
\hline $\begin{array}{l}\text { Rangchuet } \\
\text { (รางจืด) }\end{array}$ & $\begin{array}{l}\text { Thunbergia } \\
\text { laurifolia Lindl. }\end{array}$ & $\begin{array}{l}\text { Both fresh and } \\
\text { dried sample, } \\
\text { powder }\end{array}$ & 10 & $N Q$ & Nil & Bar-HRM analysis & $\begin{array}{l}\text { Singtonat and } \\
\text { Osathanunkul, } \\
2015\end{array}$ \\
\hline
\end{tabular}

NQ, Not quantified; N/A, Not applicable.

mixtures of powdered CPMs for authentication, and other CPMs were generated through substitutions or as adulterants (Gao et al., 2017). Zhang et al. (2017) used SNPs for which traditional DNA barcoding has not been successful for the differentiation of Echinacea species.

Loop-mediated isothermal amplification (LAMP) is one of the approaches developed to identify herbal medicine species (Li et al., 2016). A study demonstrated that the recombinase polymerase amplification (RPA) assay can be developed into an efficient tool for the rapid on-site authentication of plant species in Ginkgo biloba herbal products to differentiate the two species G. biloba and Sophora japonica (as adulteration) (Liu et al., 2018). DNA barcoding and metabarcoding have potential for the quality control of herbal products (Raclariu et al., 2018). Recently, a study recounted the history of DNAbased methods for identification of botanicals, discussed some of the difficulties in defining a specific barcode or codes to use, and described how next generation sequencing technologies have enabled new techniques that can be used to identify these products with great authority and resolution (Moraes et al., 2015). High-throughput sequencing (HTS) methods were used effectively in the quality control and identification of food components. The HTS platforms, Illumina, and Ion Torrent, were used for the analysis of herbal teas, which yielded congruent results, both qualitatively and quantitatively (Speranskaya et al., 2018). These studies confirm that species admixtures may occur in the raw herbal trade. An intrinsic problem associated with the adulteration of herbal products is the effect it may have on user health and safety (Valiathan, 2006; Seethapathy et al., 2015; Srirama et al., 2017). Without regulation, such adulteration will decrease the efficacy and consumer confidence in herbal products, which will eventually cause economic damage to the raw herbal trade (Srirama et al., 2017). 


\section{Policies and Regulations Concerning Herbal Medicines}

Recently, the large-scale international trade of herbal products has increased the concern for the safety and efficacy of herbal products (Walker and Applequist, 2012; Newmaster et al., 2013; Techen et al., 2014; Srirama et al., 2017). Since most herbal medicines are used in crude formulas in combinations of several herbs and often have extended usage, it is important that the species being used undergo strict validation, safety assessment, and quality and regulatory approval, similarly to modern medicinal drugs (Srirama et al., 2017). With continued development and improvements in DNA barcoding technology, especially with the combination of highthroughput techniques developed for DNA barcoding, a large number of samples can be assessed (Srirama et al., 2017). This technology could ensure the validation of raw herbal products and the identification of a large number of species via DNAbased methods (Srirama et al., 2017).

Although herbal medicines are widely used in healthcare systems for the treatment, diagnosis, and control of disease, quality control and proper regulation remain the foremost challenges worldwide. Every nation has its own official compendiums detailing the standardization and quality procedures for traditional medicine production. Although the WHO has passed stringent regulations related to traditional product production and formulation, very few countries have implemented regulations for herbal medicines, and most countries do not have proper guidelines for botanicals. Therefore, the quality of traded medicinal herbal products is not guaranteed (WHO, 2017).

Thailand became the 26th member of the WHO in 1984, which was a year after the Adverse Drug Reaction Monitoring Center (ADRMC) was associated under the authority of the Thai Food and Drug Administration (Thai FDA) (WHO, 2017). The Thai FDA collects reports from health product surveillance systems and programs through a database, Thai herbal database. The Thai herbal database is a potentially effective data source for identifying adverse events related to herbal products (Saokaew et al., 2011). This database provides specific data with respect to the adverse status of a particular plant species (http:// thaihpvc.fda.moph.go.th/thaihvc/index.jsf\#). However, there is an immediate need for a quality check portal before it reaches the consumer.

\section{Quality Control: Centralized Testing Laboratory Proposition}

Natural products are gaining popularity each day due to their safety and availability at an affordable price. The words "herbal," "natural," and "plant-derived" can be misleading at times, and it is important for the public to be made aware that herbal mixtures are medicines in their own right (Fan et al., 2012). Herbal medicinal preparations are formulations commonly consisting of 5 to 15 different herbs or a complex formulation consisting of several medicinal herbs and chemical drug constituents. A single herbal medicine may contain many natural constituents and/or a combination of numerous herbs that can give rise to interactions with hundreds of natural ingredients (Choi et al., 2002). This demands multiple stages of assessment of herbal extracts or products, such as pharmaceutical documentation, toxicology studies, and clinical studies for quality, safety, and efficacy, before entering the market.

A strong regulatory mechanism must be implemented to screen the safety, identity, and quality of herbal products (Srirama et al., 2017). Central to such a regulatory structure is the establishment of an effective entity to evaluate the credibility of species, assess the authenticity of the raw herbal products, and connect these data with trade regulators, both nationally and internationally. To safeguard the integrity of herbal trade, trade partners may need to access and utilize a biological reference guide developed through molecular diagnostic tools coupled with metabolite profiling. Ensuring herbal medicine quality also makes the products safer and more reliable, efficacious, sustainable, and marketable (Srirama et al., 2017). Imports and exports can be governed by such validations certified by nationally recognized government bodies/agencies (Figure 1). It is important that such a governing body also sets up a regulatory system wherein both traditional medicinal plants and their herbal products are placed. Furthermore, it is important that the molecular tools (DNA sequences) and chemical metabolite profiles are also available along with the herbal plant samples (Srirama et al., 2017). These tools would provide a simple reference for validation. However, Thai medicinal products containing mixtures of numerous herbs make it difficult, time consuming, and expensive to meet the requirements of identification (both by DNA-based and metabolite-based methodologies). However, with the emergence of new technologies, especially next-generation and high-throughput techniques, a large number of samples can be evaluated through meta-barcoding and chemical analysis. In addition to the potential for frequent authentication of herbal products, this setup can also identify a wide variety of medicinal plant species.

Safe and stable herbal extracts may be marketed if their therapeutic use is well documented and certified by a CT laboratory. There is an urgent need to develop a digital key that would enable easy identification of medicinal plants and their products, which could integrate floristic details, trade, drug databases, and DNA barcoding information (Figure 2). Electronic access to such database information can be made possible with internet access and international data sharing efforts, where a wealth of chemical and DNA sequence information can be made available and samples be compared. Users can easily search and compare by plant name or drug name to obtain complete details.

\section{Conclusions}

Medicinal plants and their products are extensively used in the indigenous and modern healthcare systems in Thailand and many countries. The international trade of herbal products has a major impact on the international economy, and the demand for herbal products is growing in both 


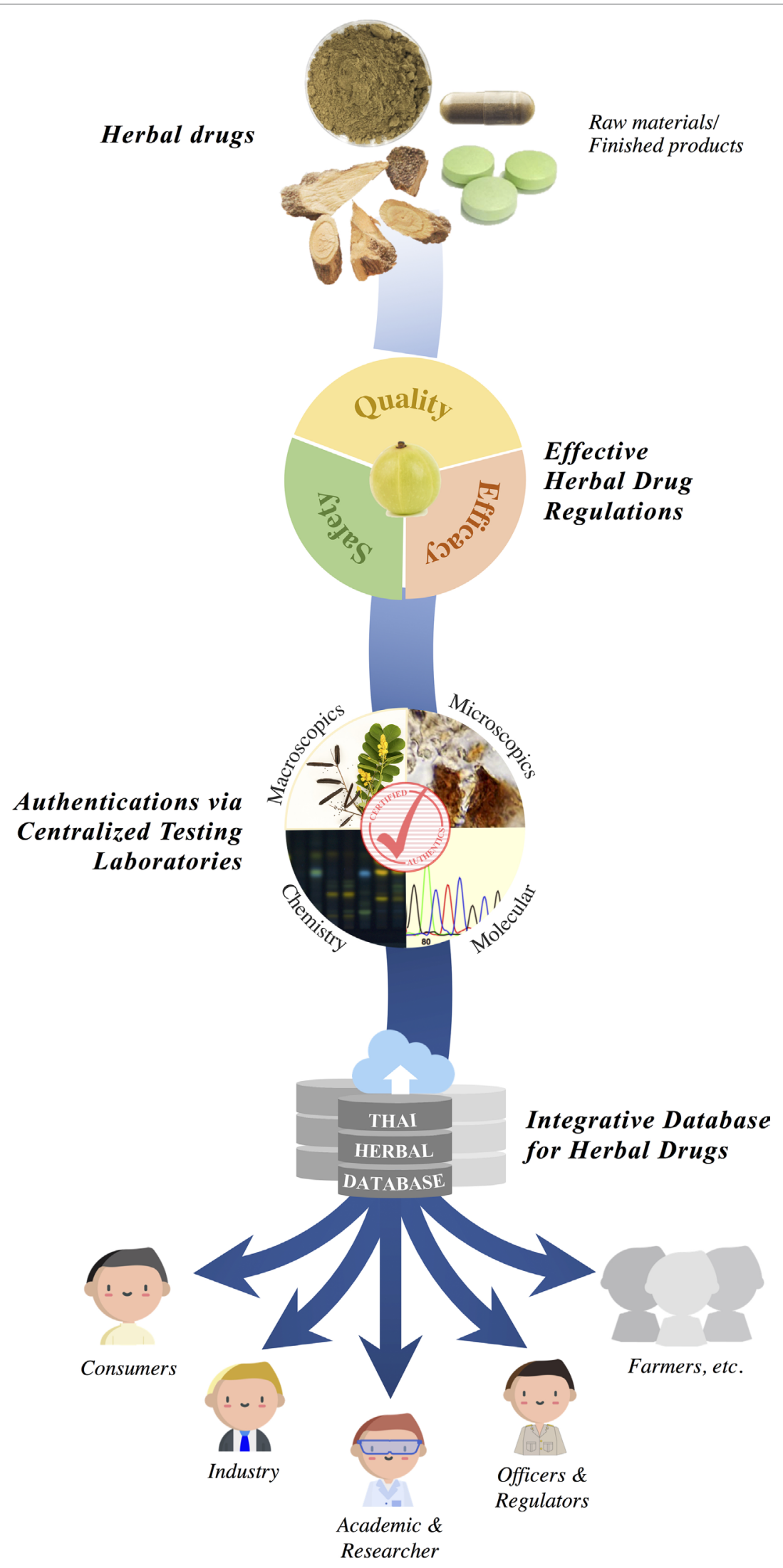

FIGURE 1 | Proposed regulatory framework of traded herbal drugs of Thailand. 
RESEARCH UNIT OF DNA BARCODING OF THAI MEDICINAL PLANTS CHULALONGKORN UNIVERSITY

\section{Thai Herbal Database}

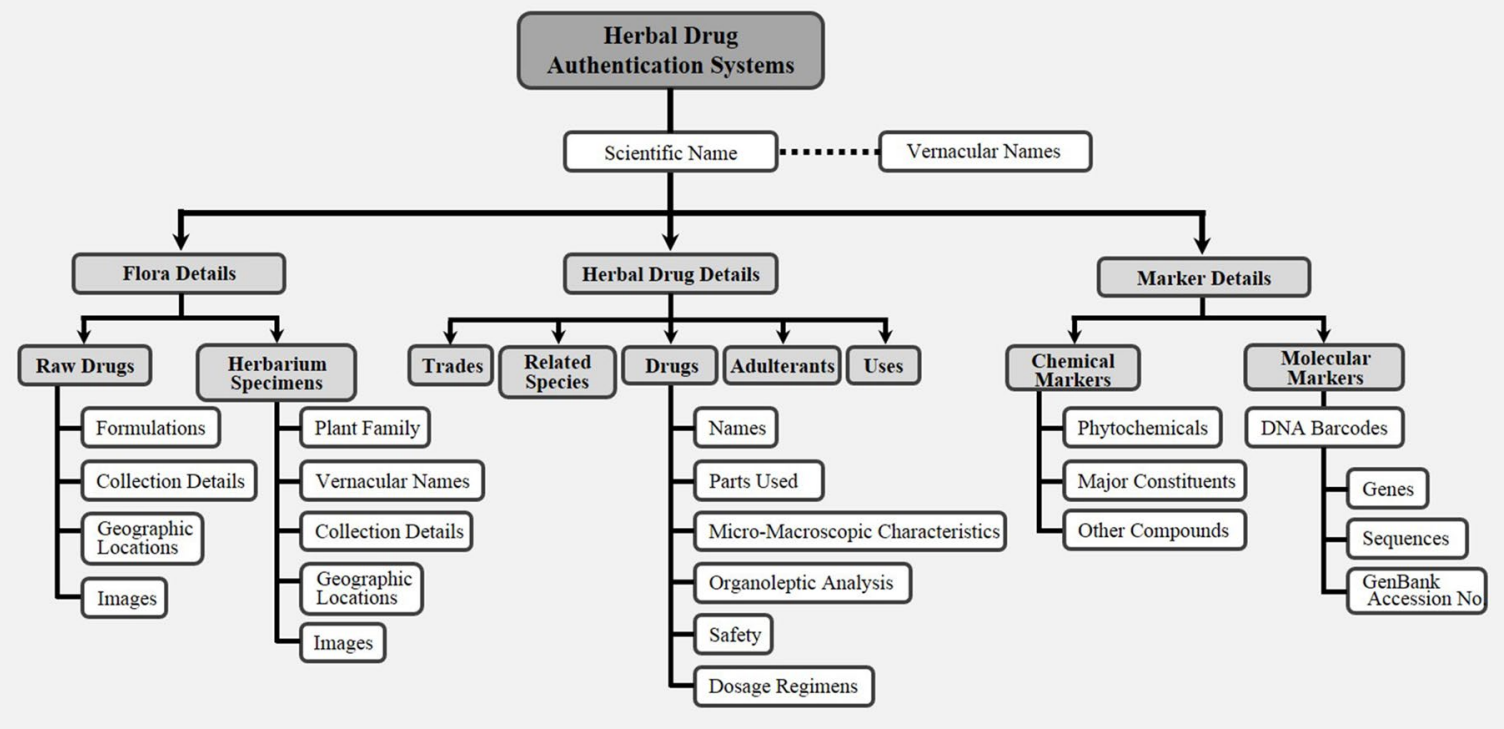

FIGURE 2 | Schematic representation of the Thai Herbal database.

developing and developed countries. This increase in demand has resulted in the substitution and adulteration of medicinal plants with other herbal products whose health benefits are unknown. The results of this study would potentially be useful in providing recommendations to address the increasing concerns of adulteration in raw drug trade and to propose mechanisms that can ensure quality standards in raw drug markets.

Our observations clearly support the claim that there is no established mechanism to connect and coordinate the herbal industry for the certification of herbal products in Thailand. Therefore, we propose the Thai herbal database that contains data on all medicinal plants, including floristic details such as taxonomic hierarchy, vernacular names in various languages, habitat, cultivation type, worldwide distribution maps, Thailand distribution maps (state and district), species images, herbarium images, general photographs, line diagrams, and synonyms. Genetic data include DNA marker information, gene sequences, GenBank accession number details, and chemical data include details of various kinds of tests such as TLC identity test, gas chromatography, gas liquid chromatography, and estimation of chemical compounds in drugs using HPLC and a complete list of major chemical constituents (marker compounds). It also contains a list of other chemical constituents and possibly important chemical compound structures as well as the status of import-export trade and the details of admixtures found in those particular plants. This database could play an important role in monitoring the medicinal plant trade and could be a promising initiative in Thailand for the development of science and technology and to provide consumers with access to all essential information. This herbal database concept could be a novel strategy in Thailand, generating transparency for all safety and quality measures and facilitating the prevention of admixtures in the herbal trade. This herbal database should be developed with utmost planning and made available to all researchers, academicians, people involved with regulatory policy and industry, and, most importantly, common people so that they may gain access to past and present studies. Additionally, in our opinion, accessibility of this herbal database to all researchers, traders, and consumers will allow the sensible development of drug safety measures. The use of this concept can allow governing bodies to improve the efficacy of herbal drugs at a considerable cost.

\section{AUTHOR CONTRIBUTIONS}

Conceptualization and design of the study: SS and SK. Data collection and formal analysis: SK. Validation and visualization: SK and CT. Conclusion: SS. Manuscript writing: SK. Review and editing: SS and SK.

\section{FUNDING}

The Ratchadaphisek Somphot Endowment Fund, Graduate School, Chulalongkorn University provided funding which was used to assist in the preparation of this review. 


\section{REFERENCES}

Abubakar, B. M., Salleh, F. M., Shamsir Omar, M. S., and Wagiran, A. (2018). Assessing product adulteration of Eurycoma longifolia (Tongkat Ali) herbal medicinal product using DNA barcoding and HPLC analysis. Pharm. Biol. 56 (1), 368-377. doi: 10.1080/13880209.2018.1479869

Akarasereenont, P., Datiles, M. J., Lumlerdkij, N., Yaakob, H., Prieto., J. M., and Heinrich, M. A. (2015). "South-east asian perspective on ethnopharmacology," in Ethnopharmacology. Eds. Heinrich, M., and Jäger, A. K. (Chennai: John Wiley \& Sons Ltd.), 317-329. doi: 10.1002/9781118930717.ch27

Arunraj, R., Abiramavalli, M., and Rathinasabapathi, P. (2016). DNA barcoding identifies the component species in the powder formulations of plant derived raw drugs sold in retail market in India. Res. J. Biotechnol. 11, 100-107.

Barry, J., and Abratt, R. (2015). "Relationship strength and quality in industrial services: a global empirical study, in Marketing, technology and customer commitment in the new economy. Ed. Spotts, H. (Cham, Switzerland: Developments in Marketing Science: Proceedings of the Academy of Marketing Science), 141-141. doi: 10.1007/978-3-319-11779-9_49

Bruni, I., De Mattia, F., Galimberti, A., Galasso, G., Banfi, E., Casiraghi, M., et al. (2010). Identification of poisonous plants by DNA barcoding approach. Int. J. Legal. Med. 124, 595-603. doi: 10.1007/s00414-010-0447-3

Chen, X., Xiang, L., Shi, L., Li, G., Yao, H., Han, J., et al. (2017). Identification of crude drugs in the Japanese pharmacopoeia using a DNA barcoding system. Sci. Rep. 7, 42325(1-7). doi: 10.1038/srep42325

Choi, D. W., Kim, J. H., Cho, S. Y., Kim, D. H., and Chang, S. Y. (2002). Regulation and quality control of herbal drugs in Korea. Toxicol. 181, 581-586. doi: 10.1016/S0300-483X(02)00487-0

Cristians, S., Bye, R., and Nieto Sotelo, J. (2018). Molecular markers associated with chemical analysis: a powerful tool for quality control assessment of Copalchi Medicinal Plant Complex. Front. Pharmacol. 9, 666. doi: 10.3389/ fphar.2018.00666

de Boer, H. J., Ichim, M. C., and Newmaster, S. G. (2015). DNA barcoding and pharmacovigilance of herbal medicines. Drug Saf. 38, 611-620. doi: 10.1007/ s40264-015-0306-8

Dechbumroong, P., Aumnouypol, S., Denduangboripant, J., and Sukrong, S. (2018). DNA barcoding of Aristolochia plants and development of speciesspecific multiplex PCR to aid HPTLC in ascertainment of Aristolochia herbal materials. PloS One 13, 1-16. doi: 10.1371/journal.pone.0202625

Dhanya, K., Syamkumar, S., Siju, S., and Sasikumar, B. (2011). SCAR markers for adulterant detection in ground chilli. Br. Food J. 113 (5), 656-668. doi: 10.1108/00070701111131755

Fadzil, N., Wagiran, A., Mohd Salleh, F., Abdullah, S., and Mohd Izham, N. (2018). Authenticity testing and detection of Eurycoma longifolia in commercial herbal products using bar-high resolution melting analysis. Genes 9 (8), 408419. doi: 10.3390/genes 9080408

Fan, T. P., Deal, G., Koo, H. L., Rees, D., Sun, H., Chen, S., et al. (2012). Future development of global regulations of Chinese herbal products. J. Ethnopharmacol. 140 (3), 568-586. doi: 10.1016/j.jep.2012.02.029

Feng, T., Liu, S., and He, X. J. (2010). Molecular authentication of the traditional Chinese medicinal plant Angelica sinensis based on internal transcribed spacer of nrDNA. Elec. J. Biotechnol. 13 (1), 9-10. doi: 10.2225/vol13-issue1-fulltext-13

Galimberti, A., De Mattia, F., Losa, A., Bruni, I., Federici, S., Casiraghi, M., et al. (2013). DNA barcoding as a new tool for food traceability. Food Res. Int. 50, 55-63. doi: 10.1016/j.foodres.2012.09.036

Gao, Z., Liu, Y., Wang, X., Song, J., Chen, S., Ragupathy, S., et al. (2017). Derivative technology of DNA barcoding (nucleotide signature and SNP double peak methods) detects adulterants and substitution in Chinese patent medicines. Sci. Rep. 7 (1), 5858. doi: 10.1038/s41598-017-05892-y

Howes, M. J. R., Simmonds, M. S., and Kite, G. C. (2004). Evaluation of the quality of sandalwood essential oils by gas chromatography-mass spectrometry. J. Chromatogr. A. 1028 (2), 307-312. doi: 10.1016/j.chroma.2003.11.093

Intharuksa, A., Ando, H., Miyake, K., Sirisa-Ard, P., Mikage, M., and Sasaki, Y. (2016). Molecular analysis of terminalia spp. distributed in Thailand and authentication of crude drugs from terminalia plants. Biol. Pharm. Bull. 39 (4), 492-501. doi: 10.1248/bpb.b15-00673

Jaakola, L., Suokas, M., and Häggman, H. (2010). Novel approaches based on DNA barcoding and high-resolution melting of amplicons for authenticity analyses of berry species. Food Chem. 123, 494-500. doi: 10.1016/j.foodchem.2010.04.069
Kamboj, V. P. (2000). Herbal medicine. Curr. Sci. 78 (1), 35-39.

Kang, T. S. (2018). Identification of undeclared ingredients in red pepper products sold on the South Korea commercial market using real-time PCR methods. Food Control 90, 73-80. doi: 10.1016/j.foodcont.2018.02.033

Khan, S., Mirza, K. J., Anwar, F., and Abdin, M. Z. (2010). Development of RAPD markers for authentication of Piper nigrum (L.). Environ. We Int. J. Sci. Tech. 5, 47-56.

Kokate, C. K., Purohit, A. P., and Gokhele, S. B. (2007). Pharmacognosy. Pune, India: Nirali Prakashan.

Kool, A., de Boer, H. J., Krüger, Å., Rydberg, A., Abbad, A., Björk, L., et al. (2012). Molecular identification of commercialized medicinal plants in Southern Morocco. Plos one 7 (6), 1-12. doi: 10.1371/journal.pone.0039459

Kreuzer, M., Howard, C., Pendry, C. A., Adhikari, B., and Hawkins, J. A. (2019). Phylogenomic approaches to DNA barcoding of herbal medicines: developing clade-specific diagnostic characters for Berberis. Front. Plant Sci. 10, 586. doi: 10.3389/fpls.2019.00586

Kumar, J. S., Krishna, V., Seethapathy, G. S., Ganesan, R., Ravikanth, G., and Shaanker, R. U. (2018). Assessment of adulteration in raw herbal trade of important medicinal plants of India using DNA barcoding. 3 Biotech. 8 (135), 1-8. doi: 10.1007/s13205-018-1169-3

Kumar, J. S., Krishna, V., Seethapathy, G. S., Senthilkumar, U., Ragupathy, S., Ganeshaiah, K. N., et al. (2015). DNA barcoding to assess species adulteration in raw drug trade of "Bala" (genus: Sida L.) herbal products in South India. Biochem. Syst. Ecol. 61, 501-509. doi: 10.1016/j. bse.2015.07.024

Li, J. J., Xiong, C., Liu, Y., Liang, J. S., and Zhou, X. W. (2016). Loop-mediated isothermal amplification (LAMP): emergence as an alternative technology for herbal medicine identification. Front. Plant Sci. 7, 1956. doi: 10.3389/ fpls.2016.01956

Liu, Y., Wang, X. Y., Wei, X. M., Gao, Z. T., and Han, J. P. (2018). Rapid authentication of Ginkgo biloba herbal products using the recombinase polymerase amplification assay. Sci. Rep. 8 (1), 8002. doi: 10.1038/ s41598-018-26402-8

Lu, G. H., Chan, K., Liang, Y. Z., Leung, K., Chan, C. L., Jiang, Z. H., et al. (2005) Development of high-performance liquid chromatographic fingerprints for distinguishing Chinese Angelica from related umbelliferae herbs. J. Chromatogr. A. 1073, 383-392. doi: 10.1016/j.chroma.2004.11.080

Medicinal Plant Names Services. (2017). Portal Version 6; http://www.kew.org/ mpns [Accessed ].

Menghani, E., Jain, S. C., and Jain, R. (2010). Scientific validation of Piper nigrum by HPLC and anti-oxidative assay markers. Asian J. Biotech. 2 (2), 133-138. doi: 10.3923/ajbkr.2010.133.138

Menon, P. (2003). Conservation and consumption - a study on the crude drug trade in threatened medicinal plants in Thiruvananthapuram District, Kerala. Trivandrum: KRPLLD, CDS.

Mezzasalma, V., Bruni, I., Fontana, D., Galimberti, A., Magoni, C., and Labra, M. A. (2017). DNA barcoding approach for identifying species in Amazonian traditional medicine: the case of Piri-Piri. Plant Gene 9, 1-5. doi: 10.1016/j. plgene.2016.11.001

Mishra, P., Kumar, A., Nagireddy, A., Mani, D. N., Shukla, A. K., Tiwari, R., et al. (2016). DNA barcoding: an efficient tool to overcome authentication challenges in the herbal market. Plant Biotechnol. J. 14, 8-21. doi: 10.1111/ pbi. 12419

Mitra, S. K., and Kannan, R. (2007). A note on unintentional adulterations in Ayurvedic herbs. Ethnobot. Leaflets. 11, 11-15.

Moraes, D. F. C., Still, D. W., Lum, M. R., and Hirsch, A. M. (2015). DNA-based authentication of botanicals and plant-derived dietary supplements: where have we been and where are we going? Planta Med. 81 (09), 687-695. doi: $10.1055 / \mathrm{s}-0035-1545843$

Mukherjee, P. K. (2002). Quality control of herbal drugs. New Delhi, India: Business Horizons.

National Drug Committee (2006). List of herbal medicinal products AD2006, Available from: drug.fda.moph.go.th:81/nlem.in.th/sites/default/files/binder3. pdf.

Newmaster, S. G., Grguric, M., Shanmughanandhan, M., Ramalingam, S., and Ragupathy, S. (2013). DNA barcoding detects contamination and substitution in North American herbal products. BMC Med. 11, 222-235. doi: $10.1186 / 1741-7015-11-222$ 
Noh, P., Kim, W., Yang, S., Park, I., and Moon, B. (2018). Authentication of the herbal medicine Angelicae Dahuricae Radix using an ITS sequence-based multiplex SCAR assay. Molecules 23 (9), 1-12. doi: 10.3390/molecules23092134

Nurrulhidayah, A. F., Man, Y. B., Al-Kahtani, H. A., and Rohman, A. (2011). Application of FTIR spectroscopy coupled with chemometrics for authentication of Nigella sativa seed oil. J. Spectrosc. 25 (5), 243-250. doi: $10.1155 / 2011 / 470986$

Osathanunkul, M., Ounjai, S., Osathanunkul, R., and Madesis, P. (2017). Evaluation of a DNA-based method for spice/herb authentication, so you do not have to worry about what is in your curry, buon appetito! PloS One 12 (10), 1-12. doi: 10.1371/journal.pone.0186283

Osathanunkul, M., Suwannapoom, C., Khamyong, N., Pintakum, D., Lamphun, S. N., Triwitayakorn, K., et al. (2016). Hybrid analysis (barcodehigh resolution melting) for authentication of Thai herbal products, Andrographis paniculata (Burm.f.) Wall.ex Nees. Phcog. Mag. 12, 71-75. doi: 10.4103/0973-1296.176112

Parvathy, V. A., Swetha, V. P., Sheeja, T. E., Leela, N. K., Chempakam, B., and Sasikumar, B. (2014). DNA barcoding to detect chilli adulteration in traded black pepper powder. Food Biotech. 28 (1), 25-40. doi: 10.1080/08905436.2013.870078

Pawar, R. S., Handy, S. M., Cheng, R., Shyong, N., and Grundel, E. (2017). Assessment of the authenticity of herbal dietary supplements: comparison of chemical and DNA barcoding methods. Planta Med. 83 (11), 921-936. doi: 10.1055/s-0043-107881

Phoolcharoen, W., and Sukrong, S. (2013). Molecular analysis of Vitex species using candidate DNA barcoding and PCR-RFLP of the matK gene for authentication of Vitex glabrata. Nat. Prod. Commun. 8 (1), 125-128. doi: $10.1177 / 1934578 X 1300800130$

Phumthum, M., and Balslev, H. (2018). Thai ethnomedicinal plants used for diabetes treatment. OBM ICM 3 (3), 1-25. doi: 10.21926/obm.icm. 1803020

Raclariu, A. C., Heinrich, M., Ichim, M. C., and de Boer, H. (2018). Benefits and limitations of DNA barcoding and metabarcoding in herbal product authentication. Phytochem. Anal. 29 (2), 123-128. doi: 10.1002/pca.2732

Saokaew, S., Suwankesawong, W., Permsuwan, U., and Chaiyakunapruk, N. (2011). Safety of herbal products in Thailand. Drug Saf. 34 (4), 339-350. doi: 10.2165/11586590-000000000-00000

Sarin, Y. K. (1996). Illustrated manual of herbal drugs used in Ayurveda. New Delhi, India: CSIR \& ICMR.

Schori, M., and Showalter, A. M. (2001). DNA barcoding as a means for identifying medicinal plants of Pakistan. Pak. J. Bot. 43, 1-4.

Sciarrone, D., Costa, R., Ragonese, C., Tranchida, P. Q., Tedone, L., Santi, L., et al. (2011). Application of a multidimensional gas chromatography system with simultaneous mass spectrometric and flame ionization detection to the analysis of sandalwood oil. J. Chromatogr. A. 1218 (1), 137-142. doi: 10.1016/j. chroma.2010.10.117

SEARO, WHO (2010). The integration of Thai traditional medicine in the national health care system of Thailand. Traditional Medicine in the Kingdom of Thailand, 97-120. http://www.searo.who.int/entity/medicines/topics/ traditional_medicines_in_the_kingdom_of_thailand.pdf

Seethapathy, G. S., Ganesh, D., Kumar, J. U. S., Senthilkumar, U., Newmaster, S. G., Ragupathy, S., et al. (2015). Assessing product adulteration in natural health products for laxative yielding plants, Cassia, Senna, and Chamaecrista, in Southern India using DNA barcoding. Int. J. Legal. Med. 129, 693-700. doi: 10.1007/s00414-014-1120-z

Seethapathy, G. S., Tadesse, M., Urumarudappa, S. K. J., Gunaga, S. V., Vasudeva, R., Malterud, K. E., et al. (2018). Authentication of Garcinia fruits and food supplements using DNA barcoding and NMR spectroscopy. Sci. Rep. 8 (1), 10561(1-12). doi: 10.1038/s41598-018-28635-z

Singtonat, S., and Osathanunkul, M. (2015). Fast and reliable detection of toxic Crotalaria spectabilis Roth. in Thunbergia laurifolia Lindl. herbal products using DNA barcoding coupled with HRM analysis. BMC Complement. Altern. Med. 15, 1-8. doi: 10.1186/s12906-015-0692-6

Song, J., Yao, H., Li, Y., Li, X., Lin, Y., Liu, C., et al. (2009). Authentication of the family Polygonaceae in Chinese pharmacopoeia by DNA barcoding technique. J. Ethnopharmacol. 124, 434-439. doi: 10.1016/j.jep.2009.05.042

Song, M., Dong G-Q., Zhang, Y. Q., Liu, X., and Sun, W. (2017). Identification of processed Chinese medicinal materials using DNA mini-barcoding. Chin. J. Nat. Med. 15 (7), 481-486. doi: 10.1016/S1875-5364(17)30073-0
Song, M., Li, J., Xiong, C., Liu, H., and Liang, J. (2016). Applying high-resolution melting (HRM) technology to identify five commonly used Artemisia species. Sci. Rep. 6, 34133(1-12). doi: 10.1038/srep34133

Speranskaya, A. S., Khafizov, K., Ayginin, A. A., Krinitsina, A. A., Omelchenko, D. O., Nilova, M. V., et al. (2018). Comparative analysis of Illumina and Ion Torrent high-throughput sequencing platforms for identification of plant components in herbal teas. Food Control 93, 315-324. doi: 10.1016/j.foodcont.2018.04.040

Srirama, R., Kumar, J. S., Seethapathy, G. S., Newmaster, S. G., Ragupathy, S., Ganeshaiah, K. N., et al. (2017). Species adulteration in the herbal trade: causes, consequences and mitigation. Drug Saf. 40 (8), 651-661. doi: 10.1007/ s40264-017-0527-0

Stoeckle, M. Y., Gamble, C. C., Kirpekar, R., Young, G., Ahmed, S., and Little, D. P. (2011). Commercial teas highlight plant DNA barcode identification successes and obstacles. Sci. Rep. 1, 42(1-7). doi: 10.1038/srep00042

Sudhir, S. P., Kumarappan, A., Vyas, L. K., Shrivastava, D., Deshmukh, P., and Verma, H. N. (2016). Identification of Nigella sativa seed and its adulterants using DNA barcode marker. AJLS 4 (5), 118-128. doi: 10.11648/j. ajls.20160405.14

Sunita, G. (1992). Substitute and adulterant plants. New Delhi, India: Periodical Experts Book Agency.

Suwanchaikasem, P., Phadungcharoen, T., and Sukrong, S. (2013). Authentication of the Thai medicinal plants sharing the same common name 'Rang Chuet': Thunbergia laurifolia, Crotalaria spectabilis, and Curcuma aff. amada by combined techniques of TLC, PCR-RFLP fingerprints, and antioxidant activities. Sci. Asia 39, 124-133. doi: 10.2306/ scienceasia1513-1874.2013.39.124

Tangjitman, K., Wongsawad, C., Kamwong, K., Sukkho, T., and Trisonthi, C. (2015). Ethnomedicinal plants used for digestive system disorders by the Karen of northern Thailand. J. Ethnobiol. Ethnomed. 11 (1), 27. doi: 10.1186/ s13002-015-0011-9

Techen, N., Crockett, S. L., Khan, I. A., and Scheffler, B. E. (2004). Authentication of medicinal plants using molecular biology techniques to compliment conventional methods. Curr. Med. Chem. 11, 1391-1401. doi: 10.2174/0929867043365206

Techen, N., Parveen, I., Pan, Z., and Khan, I. A. (2014). DNA barcoding of medicinal plant material for identification. Curr. Opin. Biotech. 25, 103-110. doi: 10.1016/j.copbio.2013.09.010

Trisonthi, C., and Trisonthi, P. (1995). Ethnobotany of Karen at Mae Hae Nua, Mae Na Chorn, Mae Chaem District, Chaiang Mai Province (in Thai). OBM ICM 3 (3), 1-25.

Tungphatthong, C., Somnuek, J., Phadungcharoen, T., Ingkaninan, K., Denduangboripant, J., and Sukrong, S. (2018). DNA barcoding of species of Bacopa coupled with high-resolution melting analysis. Genome 61 (12), 867-877. doi: 10.1139/gen-2018-0059

Uniyal, M. R., and Joshi, G. C. (1993). Historical view of the basic principles of the identification of controversial drugs, problems and suggestions. Sachitra Ayurved 45, 531-536.

Urumarudappa, S. K. J., Gogna, N., Newmaster, S. G., Venkatarangaiah, K., Subramanyam, R., Saroja, S. G., et al. (2016). DNA barcoding and NMR spectroscopy-based assessment of species adulteration in the raw herbal trade of Saraca asoca (Roxb.) Willd: an important medicinal plant. Int. J. Legal. Med. 130 (6), 1457-1470. doi: 10.1007/s00414-016-1436-y

Valiathan, M. S. (2006). Ayurveda: putting the house in order. Curr. Sci. 90, 1.

Ved, D. K., and Goraya, G. S. (2007). Demand and supply of medicinal plants in India. Bangalore, India: NMPB, New Delhi \& FRLHT.

Vejayan, J., Mohamed, A. N., Zulkifli, A. A., Yahya, Y. A. C., Munir, N., and Yusoff, M. M. (2018). Marker to authenticate Eurycoma longifolia (Tongkat Ali) containing aphrodisiac herbal products. Curr. Sci. 115 (5), 886-894. doi: $10.18520 / \mathrm{cs} / \mathrm{v} 115 / \mathrm{i} 5 / 886-894$

Wakdikar, S. (2004). Global health care challenge: Indian experiences and new prescriptions. Elec. J. Biotechnol. 7, 214-220. doi: 10.2225/vol7-issue3-fulltext-5

Walker, K. M., and Applequist, W. L. (2012). Adulteration of selected unprocessed botanicals in the U.S. retail herbal trade. Econ. Bot. 66, 321-327. doi: 10.1007/ s12231-012-9211-6

Wang, X., Liu, Y., Wang, L., Han, J., and Chen, S. (2016). A nucleotide signature for the identification of Angelicae Sinensis Radix (Danggui) and its products. Sci. Rep. 6, 34940. doi: 10.1038/srep34940 
Wieniawski, W. (2001). Risk assessment as an element of drug control. WHO Drug Info. 15, 6 .

World Health Organization. (2002). WHO Traditional Medicine Strategy 2002-2005. Geneva: WHO. http://herbalnet.healthrepository.org/bitstream/ 123456789/2028/1/WHO_traditional_medicine_strategy_2002-2005.pdf.

World Health Organization. (2017). The pharmacovigilance system for traditional medicine in Thailand (No. SEA-HSD-393). New Delhi, India: WHO, Regional Office for South-East Asia.

Xie, P., Chen, S., Liang, Y. Z., Wang, X., Tian, R., and Upton, R. (2006). Chromatographic fingerprint analysis-a rational approach for quality assessment of traditional Chinese herbal medicine. J. Chromatogr. A. 1112, 171-180. doi: 10.1016/j.chroma.2005.12.091

Xin, T., Xu, Z., Jia, J., Leon, C., Hu, S., Lin, Y., et al. (2018). Biomonitoring for traditional herbal medicinal products using DNA metabarcoding and single molecule, real-time sequencing. Acta Pharm. Sin. B. 8 (3), 488-497. doi: 10.1016/j.apsb.2017.10.001

Yu, N., Wei, Y. L., Zhang, X., Zhu, N., Wang, Y. L., Zhu, Y., et al. (2017). Barcode ITS2: a useful tool for identifying Trachelospermum jasminoides and a good monitor for medicine market. Sci. Rep. 7, 5037. doi: 10.1038/ s41598-017-04674-w

Zhang, N., Erickson, D. L., Ramachandran, P., Ottesen, A. R., Timme, R. E., Funk, V. A., et al. (2017). An analysis of Echinacea chloroplast genomes: implications for future botanical identification. Sci. Rep. 7 (1), 216. doi: 10.1038/s41598-017-00321-6

Conflict of Interest: The authors declare that the research was conducted in the absence of any commercial or financial relationships that could be construed as a potential conflict of interest.

Copyright () 2019 Urumarudappa, Tungphatthong and Sukrong. This is an openaccess article distributed under the terms of the Creative Commons Attribution License (CC BY). The use, distribution or reproduction in other forums is permitted, provided the original author(s) and the copyright owner(s) are credited and that the original publication in this journal is cited, in accordance with accepted academic practice. No use, distribution or reproduction is permitted which does not comply with these terms. 